\title{
The "mild-torture economy": exploring the world of professional research subjects and its ethical implications
}

\section{| ${ }^{1}$ Roberto Abadie |}

Abstract: This paper documents the emergence of the subject of professional research in Phase I clinical trials that test the safety of drugs in development. Based on ethnographic research among subjects self-identified as "professional guinea pigs" in Philadelphia, USA, it examines their experiences and opinions on the conduct of trials and risks they take. The author argues that the risks posed by the continued participation, such as exposure to potentially dangerous drug interactions are minimized or ignored by research subjects because of the prospect of financial gain. Risks to the professional guinea pigs are also ignored by the pharmaceutical industry, which has become dependent on the usual participation of experienced research subjects. Arguing that financial incentives undermine the ethical imperative of informed consent to be given freely by volunteers, this research confirms the need to reform the policies governing the participation of paid subjects in Phase I clinical trials.

> Key words: clinical trials; human subjects; risk; ethics; qualitative research. 


\section{Introduction: the mild-torture economy}

Spam was a West Philadelphia resident who had participated in multiple drug trials as a healthy, paid research subject, as a "guinea pig." When I met him, in his early thirties, after he had quit the trials and began working as a union organizer, he offered his insights on what was it like to participate in what he calls the "mild-torture economy" as a paid subject:

$[\mathrm{M}]$ anufacturing has been taken off, outside the country, so you are not allowed to do things any more. They call it the "new economy," the "informational economy." And the other side of this informational economy is the mild-torture economy-you are not asked to produce or to do something anymore, you are being asked to endure something. So, if you are a guinea pig, you are enduring something, people are doing things to you and you are just enduring it, you are not actually producing something. I feel that I am a worker but it is not work, it's like a security guard that does not produce nothing, just watches stuff. A security guard just gets paid to be bored; it's about how much can you deal with being bored, that's the real hard part of it, the time and discomfort of being there. But it's different when you are in a cleaning job, [then] I am doing something. But being a guinea pig is just being paid to endure something that happens to me, which is weird. It's a different type of activity; I still feel that there is some work in it but the nature of work has changed. And I am letting people pay me in exchange [for] the control they have over me.

Boredom and discomfort are characteristic of many low paying, low skilled occupations, and security work perhaps epitomizes these types of jobs, as Spam suggests, with guards paid (to pretend) to be alert at all times. And, to be sure, the alienation felt by professional research subjects might not be different than that felt by workers in other occupations who also experience a lack of purpose or control over their daily routines and the results of their labor. But what is different in the case of professional research subjects, or "professional guinea pigs" as they call themselves, is that the ethics involving human subjects in biomedical research elicits serious attention. While exploitation in other domains seldom raises any ethical questions, "human subjects protections" are very much the concern of bioethicists, institutions that host research, from universities to pharmaceutical companies, and the oversight committees charged with ensuring that proper procedures are carried out.

The participation of paid human volunteers in clinical trials poses many questions in relation to financial compensation, risks, and ethical regulations, some of which have not yet been adequately examined. Does monetary compensation affect the way volunteers think about risks and benefits, unduly 
enticing them to participate? Or, do professional guinea pigs gain an increased awareness of risks through long-term participation in drug trials? Are existing ethical frameworks enough to protect paid subjects, especially during Phase I trials? Finally, even if subjects are aware of the risks they face and their rights as subjects, are they not being exploited anyway as the weakest link in the trial economy? (ABADIE, 2010).

\section{The emergence of the "professional guinea pig"}

New drug compounds are first tested in animals, usually dogs or rats - because such animals are cheap - and, if the drugs show promise, then in Phase I trials, involving a small group of between 30 and 100 healthy subjects. If the drug proves to be safe it then goes to Phases II and III, which usually involve a much larger group of patients - sometimes in the thousands - with the condition that the drug is supposed to be improved through this process. The compound continues to be tested for safety while its therapeutic value is assessed. Most compounds are abandoned during Phase I due to their toxicity and only a handful of drugs make it through all four of the research phases. The process of moving a drug from the lab to the market usually takes between 12 and 15 years and hundreds of millions of dollars. Since production costs are so low, the drugs that successfully make it to market more than compensate the pharmaceutical industry for their research and development expenses, making them one of the most profitable industries in the country.

Recruiting and paying healthy research subjects in the United States is a relatively new phenomenon. Until the mid-seventies, Phase I trials were conducted on prisoners. In many ways this group constituted a perfect research subject - captive, relatively compliant, and readily available — and the prison setting provided an almost perfectly controlled environment. However, abuses and renewed ethical concerns over prisoners' capacity to give un-coerced consent brought the practice to a halt.

The pharmaceutical industry was then forced to find a new population for drug trials, which were increasing in number as the industry grew. The drugs tested range from compounds never tried before in humans, called "first in men" drugs, to bioequivalence trials for drugs already on the market, like painkillers or more risky drugs like psychiatric medications. Paying healthy volunteers to 
test their drugs was the way they found to replenish the pool of research subjects. Initially, students, artists, the unemployed, and other groups explored this new source of income. Some appreciated the opportunity to earn an income in this way, and began volunteering on a regular basis. Not only did subjects become dependent upon drug trial income but the drug companies increasingly came to appreciate having experienced trial subjects who were knowledgeable about the procedures and who were willing to cope with the depersonalization, pain, and boredom that so often accompany the drug trial experience. The pharmaceutical industry started enticing these research subjects with larger payments, ads, and targeted mailings. As a result, a new occupational category was developed: the professional guinea pig.

During my research, ${ }^{1}$ I learned that in most cases the prospect of financial compensation is the guinea pig's only motivation to participate in the trial economy. In Philadelphia, a hotbed for clinical trials, payment might range from $\$ 1,200$ for three or four days in less intensive trials, to $\$ 5,000$ for volunteering for three or four weeks; on occasion a trial might need even more time to be completed, with even higher payments. Trials that involve unusual and uncomfortable procedures or that test psychiatric drugs tend to pay relatively more, in an attempt to attract research subjects who might be more reluctant to undergo discomfort and face increased risk.

Sometimes volunteers shift between participating in drug trials and working low-paying jobs as cooks, construction workers, house painters, or bike messengers. But for many participants, the trials become their full-time job; such volunteers might enroll in five to eight trials a year, and receive a total estimated income of $\$ 15,000$ to $\$ 20,000$ in good years. Some experienced research subjects I met had participated in 70,80, or even more Phase I trials over the course of a few years. As one experienced professional guinea pig admitted: "You became addicted to the trials, to the easy money." This group constitutes the backbone of Phase I clinical trials in the United States, and should be distinguished from other volunteers such as those affected by particular diseases or conditions, their family members, or even disease activists who volunteer to participate. These other types of volunteers are typically motivated by altruistic, personal, or even political goals, and only rarely by financial concerns. 
Professional research subjects understand their social identity not as a "paid volunteer," as proposed by the pharmaceutical industry, but as workers. They understand that their bodies are valuable commodities. "Commodities, like persons, have social lives,” notes Arjun Appadurai (APPADURAI, 1986, p. 3). Karl Marx also understood this aspect of commodities, prompting us to consider "what we might learn if commodities could speak" (MARX, p. 1976). In the case of professional guinea pigs, in opposition to most commodities and in particular to the drugs they help develop, we can ask; they do speak and not just in a metaphorical sense. And while they can articulate their experience in words, their bodies also are sites where the social and cultural processes that have produced the emergence of professional research subjects are manifest.

As scholars have shown, embodiment adopts very particular forms (CSORDAS, 1994; LOCK; FARQUHAR, 2007). Many professional guinea pigs I met bear "battle scars." I was impressed by one young man in his late thirties, KingLabRat, and his needle scars in both arms. He was born and raised in Florida by Puerto Rican parents, and had been doing trials since his early twenties, touring the country in search of good trial opportunities. One of the most experienced guinea pigs, his chosen moniker, which identified him as among the royalty of experimental subjects, mockingly described his more than two decades of trial participation. His scars were the result of this engagement, which had started in the 1980s, at a time when catheters were discouraged to prevent the possibility of injury or infection, thus subjecting volunteers to innumerable needle punctures. Michael, my roommate, who started volunteering much later on, in his twenties, had no such needle marks in his arms. But he still bore scars. He once showed me his back, where he was marked from a trial that required a biopsy. Pointing to the scars, he said dismissively, "I'll carry them forever. That's why they [the pharmaceutical industry] pay so well".

But paid research subjects reveal more than their scars. As "mindful bodies" (SCHEPER-HUGH; LOCK, 1987), they not only show their social trajectories as trial subjects, but volunteers themselves also are able to reflect upon what it means to be a professional guinea pig. One of the most important critiques of the pharmaceutical industry and the commoditization of bodies in clinical trials is that this trade not only exploits but also dehumanizes volunteers. The 
metaphorical identification with an animal — guinea pig — conveys well this notion of the disembodied self. It's not unusual for volunteers to invoke images of torture, sex work, or prostitution when describing their activities as volunteers. In turn, their emergent professional solidarity, their identification as professionals - albeit ones who perform a "weird" sort of work, "paid to endure," as Spam notes - and their everyday forms of resistance at work all draw attention to their efforts to reassert their human condition.

\section{Approaching anarchist guinea pigs}

I carried out 18 months of ethnographic research in Philadelphia among research subjects volunteering in clinical drug trials. Historically, Philadelphia has been a major site for pharmaceutical research. The development of the pharmaceutical industry was shaped by its interaction with one of the first medical schools in the country, located in Philadelphia (SILVERMAN, 1974). This process served as a model for transformations in the pharmaceutical industry that preceded and shaped larger national and international developments in the field (LIEBENAU, 1987). Large pharmaceutical companies such as Glaxo, Smith and Kline (GSK), Wyeth, Bristol Meyers, and Merck all currently operate in the area and formed part of this research. The city and the larger metropolitan area provide exceptional opportunities for enterprising professional research subjects.

This ethnographic study focused on a group of white male anarchists, selfdefined "professional guinea pigs," all living in West Philadelphia and volunteering mainly in metropolitan Philadelphia for Phase I trials. I found the members of the anarchist guinea pig community in Philadelphia to be very articulate and vocal about their views regarding their participation as trial subjects, the corporate practices of the pharmaceutical industry, and even the role of governmental regulation in clinical trials research. They emphasized not only the abuse and exploitation of clinical subjects in biomedical research but were also proud of their historical contribution to scientific progress. The group was also very vocal about their trial experiences, displaying a strong position on the ethics of clinical trials and thus helping to shape a public culture of guinea pigs.

One of the most experienced, articulate, and committed members of this community, Robert Helms, had participated in more than 80 trials before being forced to stop a few years ago due to an age limit restriction of 45 , imposed 
by the pharmaceutical industry. A graduate with a bachelor's degree in history

from Temple University and a former labor organizer in the health care sector, Helms edited a zine, an independent journal, for professional human subjects named Guinea Pig Zero or GPZ, from 1996 to 2002. Its success led him to publish anthology in 2003. Helms described the publication - which received the collaboration of numerous local fellow guinea pigs - as an anarchist project intended to give voice to the experiences and concerns of professional human subjects in clinical trials research. I was interested in the relationship between the group's political views and their experiences as trial subjects, and particularly about social identity, risk, and the commoditization of bodies. Just a few months before I met Helms, in the early days of my fieldwork, he and two other radical guinea pigs had played a key role in the first known strike at a Phase I clinical trial at Jefferson Hospital, a research site that does clinical trials for Merck, a pharmaceutical company. He was very excited about this event when I first met him, and I realized that the strike and the role the anarchist volunteers played in it presented an opportunity to explore not only their experiences of drug trials but also their responses to some of the conditions they faced. This event reaffirmed my choice to study this particular group of volunteers, who became the main focus of my research.

This sample of volunteers participating in clinical trials research is not representative of the universe of individuals that participate in Phase I research. Unfortunately, there is also no reliable information about the demographic data regarding the composition of this population. While the FDA publishes a list of all the drugs that receive approval in a given year, pharmaceutical companies are not required to disclose the number of trials being performed or the number of volunteers enrolled, and there is no centralized register of trial participants. Subjects remain essentially invisible, hidden.

While there are no demographic statistics about research subjects in Phase I trials, most volunteers regularly enrolled in trials in the metropolitan area of Philadelphia are poor, relatively uneducated, and from African American and Latino backgrounds. In some trials, the white anarchists I studied were a very marginal presence, and in many trials they were not present at all.

And while all professional volunteers share some common experiences, racial and ethnical differences may also shape the way they understand and deal with 
risk. For this reason I wanted to have a glimpse into the way professional guinea pigs from different racial and ethnic groups might deal with these issues. I knew that many professional subjects travel across the country looking for trial opportunities, and while they do so they often stay at cheap hostels. I stayed at a youth hostel in downtown Philadelphia, on Baker Street, for my first month of fieldwork. There I met KingLabRat, a Latino guinea pig from Tampa, Florida. In his mid-thirties, he was a discharged soldier, former drug dealer, and even a former morgue worker, but he had been touring the country in search of trials for most of his adult life. I lived with KingLabRat at the hostel, witnessing his preparations for the trial. I sought any chance to interview him throughout his trial participation, especially at key moments like his initial trial screening and his "discharge," once the trial was over. We kept in touch and in this way I was able to join him months later when he came back to the city to enroll in a new trial.

At the same time I was aware that, while males are the majority of participants recruited for Phase I clinical trials research, women have some occasions to participate as well. I also contacted women in this community, to assess if gender made any difference in the way they experienced their trial engagements.

Having volunteered as a paid human subject for a couple of Phase I clinical trials myself, I had some insight into the lives of volunteers in pharmaceutical clinical trials (ABADIE, 2008). Our shared experiences and sensibilities allowed other volunteers to interact with me at a common level of understanding and trust. Because of this, I had a point of entry into their views and feelings not accessible by other research methods, such as questionnaires or semi-structured interviews.

I used multiple methods to collect data, primarily a combination of participant observation and formal and informal interviews. In typical ethnographic fashion, eliciting my informants' comments on events and observing volunteers as they moved in and out of the trials and back into their everyday lives was a central aspect of my research. I relied heavily on observing the professional guinea pigs' activities outside the trial locations. I was able to live amidst a group of them for more than a year in a very tight-knit community of professional research subjects and had ample opportunities to document how they prepared for the trials, as well as their expectations, anxieties, and views. I followed prospective volunteers to their screening appointments, interviewed them after they had completed the first portion of the trial, or "leg" — usually after a week or so, usually as in-patients 
— and again at the end of the trial. The goals, risks, and benefits of a trial are typically disclosed to participants mainly through the consent form volunteers sign at the beginning of the trial, after enrollment. Discussing the information contained in these documents as close to the moment that volunteers signed it afforded a unique window into their perspectives on risk and its relation to financial compensation.

In addition to participant observation, I conducted 18 semi-structured interviews with self-identified professional guinea pigs. This technique allowed me to explore issues of financial compensation, risk perception, and risk management in greater depth. While this method was useful for capturing general views about the ways risks are perceived and dealt with by subjects, it cannot account for individuals' experiences of a trial. For this, I elicited six life stories from a smaller group of volunteers, according to a combination of the following criteria: length and frequency of participation, types of trials in which the person has volunteered, and risks experienced during previous trials, if any. I inquired about their personal experiences in clinical trials and their understanding of risks, focusing on the relationship between their experiences of trials and any changes in risk awareness and risk management. I also obtained information concerning their views on the relationship between their willingness to take risks and their expectation of financial gain.

\section{Anthropological contributions}

In a sense, the emergence of the professional research subject, the person who repeatedly volunteers to test experimental drugs being developed by the pharmaceutical industry, brings attention to what Michaela di Leonardo terms the "exotic at home". Professional guinea pigs constitute an exotic development of technological and medical culture, with their own ethos, identities, and practices. This paper is an attempt to further consider di Leonardo's suggestion to pursue an anthropological examination of phenomena that are "hidden in plain sight around us" (DI LEONARDO, 1998, p. 10). What are the hidden problems brought by the increasing commoditization of the body in clinical trials, in the context of an emerging professional subjectivity created by new regimes of techno-science and capital accumulation (RAJAN, 2006; ROSE, 1996)? This topic however, has thus far failed to capture the imagination of many anthropologists. My research 
is the first ethnographic description of the experiences of healthy, paid, drug trial volunteers, not only in the US but anywhere.

There are many ways anthropologists have studied other aspects of this subject. Recently, pharmaceutical drugs have emerged as a field of study among anthropologists who explore commodity chains, from sites of production to an object's consumption (PETRYNA; LAKOFF; KLEINMAN, 2006). Almost all aspects of the pharmaceutical commodity chain have been studied, from marketing practices and the role of sales representatives in shaping doctors' prescription practices (OLDANI, 2004), to the cultural, economic, and political determinants of drug consumption (BIEHL, 2007; FARMER, 2004). But while clinical trials that use market-recruited subjects are the basis of drug development and patenting, anthropologists have paid little attention to the first phase of clinical drug trials (GEEST et alt., 1996). An exception is the study of the pharmaceutical industry's increasing reliance on contract research organizations (CROs) to run the daily operations of trial sites, including the recruitment of volunteers and the selection of friendly institutional review boards (IRBs) to speed up drug development in the United States (FISHER, 2008) and increasingly abroad, in countries where regulations are few or unenforced (PETRYNA, 2006). By documenting the professionalization of clinical trial subjects in the first phase of drug development, this research contributes to this emergent field of the anthropology of pharmaceuticals.

Following classical ethnographic research, this chapter documents the discourses and practices in the particular historical and sociocultural context in which research subjects live and make decisions about trials, money, risks, and benefits. Such situated knowledge is one of the strengths of anthropological inquiry, permitting a nuanced description of the forces leading to the professionalization of these trial subjects as well as the meanings, emotions, and everyday struggles involved in being a "guinea pig." By exploring the sociocultural processes that transform human bodies into valuable commodities in the form of research subjects, this ethnography contributes to both the anthropological study of the body (LOCK, 1992; LOCK; SCHEPER-HUGHES, 1987; LOCK; FARQUHAR, 2007; MARTIN, 1987) and the study of body commodification (SHARP, 2000; 2007; SCHEPER-HUGHES; WACQUANT, 2003). It also furthers our understanding of risk by emphasizing how commodification 
processes shape professional subjects' understandings and responses to risk. The rich ethnographic data illuminates current debates on biocitizenship (PETRYNA, 2002; ROSE, 2007), the ethics of human subject protection in clinical trials and in biomedical research more broadly (ELLIOT, 2010). My aim is to advance both ethical debates - which are often presented in a formal, individualistic, rational, and legalistic framework - and an approach that incorporates the cultural context in which individuals make decisions about risks and benefits (LEVIN 1989; MARSHALL, 1992; MARSHALL; KOENIG, 2004).

Finally, while formulating policy recommendations is not the main focus of my work, I do so here hoping to stimulate public debate in the hopes of leading to a necessary transformation of public policies to ensure the ethical and safe engagement of paid subjects in clinical trials research.

\section{Local knowledge and the perception and management of risk}

Volunteers operate with a hierarchical framework of risk, in which they understand certain risks as low, medium, or high risk. While influenced by scientific explanations of possible risk, as described for example in the informed consent form, professional guinea pigs' understandings of risk are also shaped by their experience and the knowledge they have gained through participating as paid subjects.

Studies that are considered to be low risk are those involving drugs that are already on the market and present few or no side effects, even at the high doses administered during the trial. A new formulation of Tylenol, or a similar pain medication, would be placed in this category; these types of trials are the most popular choice among professional guinea pigs.

Paid subjects perceive most clinical trials as presenting a moderate risk level, an evaluation they base on two elements. First, they view trials as "a carefully controlled situation," an assessment that is based on the scientific design of the trial and the ethical regulations about the use of human subjects, which they believe helps limit the level of risk. The second element shaping their perception of a moderate risk level is their conviction that serious adverse effects or dangerous situations are exceptional, an assessment based on their other trial experiences as paid guinea pigs. 
While most volunteers do not experience serious adverse effects, the uncertainties surrounding the experimental nature of the trial introduce a degree of caution in the volunteers' risk perception. Professional guinea pigs recognize that scientists do not know everything about a drug, its risks, and its side effects. Thus in my survey of risk perception, when volunteers were asked about risk levels involved in trials, they described the risk level as moderate instead of low. This characterization contrasts with the assessment of risk by non-volunteers and the general public; based on past and present abuses in biomedical and in clinical trials research, they perceive trials as being more risky.

While volunteers rank the majority of the trials as posing a medium level of risk, some trials are perceived as presenting a high risk. Volunteers rank experimental drugs as riskier than marketed drugs. In particular, those that change the immunological system and psychiatric drugs that alter the chemistry of the brain are considered to be high risk. Experimental studies involving genetic drug testing and sleep deprivation studies are also a source of major concern. The volunteers' assumption is that a marketed drug has already been tested in healthy volunteers in another Phase I trial, as well as in later phases, and by a much larger population after it has reached the market. In contrast, an experimental drug, or "first in man" drug, as it is called by volunteers, does not offer this safeguard.

Experimental drugs are generally believed to present a higher risk than nonexperimental drugs, but this assessment is relative and rests upon such factors as their chemical composition and established side effects. In some cases, an experimental drug might be perceived as less risky than a marketed drug, for example, one experimental blood thinner might be seen as less risky than a marketed psychiatric or HIV drug. HIV drugs are widely believed to be very toxic, based on the side effects listed on the informed consent forms. Of particular concern, and thus placed at the top of the risk hierarchy, are psychotropic drugs. Helms, the longtime guinea pig, elaborates on why these trials are perceived to be high risk and something to be avoided at all cost:

Psychiatric trials are for a couple of reasons very different from trials of non-psychotropic drugs because they involve your mind. You are renting your mind and your body at the same time instead of just your body. It is a completely different economic deal. Secondly, in the psychotropic drug trials, people are writing diseases into existence. You cannot fake a fast heartbeat into existence; you cannot make people believe that the heart is beating faster. I put a stethoscope on your chest and check your fucking heartbeat, that's simple. They cannot invent your blood pressure, but they 
can invent your depression, they can invent your mood. And they can change the interpretation of what you say according to what the drug market wants. The marketing department writes the label of the drug, not the fucking doctors, the scientists. It is the marketing department. And they also write the disclaimers, fight the lawsuits. Blame the disease, not the drug. Like, [a guy] is getting into middle age, a lot of time on his hands, and is getting a little raunchy. Goes into the psychiatrist for a little talk, gets put on Prozac and two weeks later he slaughters the whole family with a rifle and blows his own brains out. Tell me it is not the fucking Prozac! That is what I think, "fuck you, fuck you." And it happens over and over again and the lawsuits get buried by companies that put a lot of money to quiet people down.

Helms's strong opinion about clinical trials involving psychiatric drugs echoes other professional guinea pigs' concerns with these trials, and offers a powerful contrast to the usual, more neutral way in which they talk about risks they face in clinical trials. Following a long established Western tradition, the mind is perceived as separate from the body, a locus of reason and rationality, and something that requires greater protection, all of which give the mind a privileged position vis-a-vis other organs.

Professional guinea pigs believe that risk can be known, and then managed. While this perspective is based on their particular trial experiences and understandings, it also helps them sustain their confidence and keeps them volunteering. Using their direct knowledge of trials they create a local classification of risk, and this influences not only the way risk is constructed, but also the ways in which volunteers attempt to manage the risks they face, including how they deal with anxiety. Using these strategies, professional guinea pigs avoid trials they place at the top of their risk hierarchy, even going so far as to quit trials if risks emerge that were not foreseen.

If a trial is perceived as being very high risk, volunteers might avoid the trial altogether, though the prospect of financial compensation and their dependence on trial income might lead volunteers to do trials they would not otherwise be inclined to do. Most experienced guinea pigs have done at least one trial they perceived as "too risky," enticed by the promise of substantial financial gain. At the same time, experienced volunteers say that they have turned down a trial on at least one occasion because they felt it presented risks that were not acceptable.

For the anarchist professional guinea pig community some of these concerns are less acute than for paid subjects that come from elsewhere. Volunteers from outside the city face traveling and housing expenses, as they usually stay in cheap 
places like youth hostels before knowing if they will be accepted into the trial. Once they are accepted, the in-patient trial regimen covers most of their material needs, but this also influences their capacity to decide whether they want to stay in the trial if something does not go the way they expected. Until they get the paycheck, "they [the pharmaceutical company sponsoring the trial] have you by the balls," one Canadian volunteer told me. In contrast with volunteers from out of town, the anarchist guinea pigs in West Philadelphia are single, childless, and have their own living arrangements, and thus face less pressure to undertake risks or trial conditions they feel are not acceptable.

A more extreme version of risk management is to abandon the trial. This is a very rare measure, and professional guinea pigs use it only as a last resort. Sometimes a drug may have secondary effects that are harder to bear than the volunteers had anticipated. If the volunteer manages to show that these effects are the direct result of the trial, then he or she might be able to leave the trial, sometimes even receiving payment for the full amount, or other times a pro-rated portion of the promised payment for full participation. While there is no penalty involved in leaving the trial in such circumstances, making the case to do so is not easy, and failure to finish a trial can be financially costly for participants.

Finally, some professional guinea pigs believe that certain substances help them to "clean the blood" and to "detoxify" the body of the chemicals they absorbed during the trial. They assume that the chemical substances ingested in trials are only contained in the blood and urine. If a few days after the drug intake is finished the drug cannot be found in tests, then volunteers believe that none remains in their bodies. This assumption is shared by most professional guinea pigs, which helps to explain why they do not give a lot of attention to their "cleansing" practices other than drinking water, a standard procedure typically suggested by the nurses or doctors conducting the trials.

Volunteers do resort to other cleansing methods on special occasions, for example, after a very long and demanding trial when they fear that the drug administered had a particular toxicity, or if they are planning to do another trial soon after finishing the first. Cleansing practices are also based on local knowledge about their bodies and the interaction with the substances they encounter as volunteers. For example, unsweetened cranberry juice is a standard drink for professional guinea pigs, as it is believed to help absorb, metabolize, 
and eliminate toxic trial substances. In addition, the use of herbs like goldenseal

or marigold flowers were suggested by Guinea Pig Zero as ways of "keeping the blood fresh and clean". According to the zine, goldenseal is "said to have a dramatic cleansing power, and is recommended by herbalists for removing the toxins related to alcohol, coffee, nicotine and other substances from blood" (HELMS, p 22. 2005).

A small group of volunteers in the anarchist community sometimes attempt to implement cleansing diets by eating only apples, or yogurt, for a number of days, in the belief that this also helps "clean" their bodies. The use of herbs and organic methods of cleansing are preferred in the anarchist community. Although anarchist volunteers usually eat meat in the trials, mainly due to their lack of choice, they place a high value on vegetables, organic diets, and healing practices. Professional research subjects who are not affiliated with the anarchist group prefer instead a chemical approach, using supplements that contain iron, which helps rebuild the blood supply.

\section{Can policy better protect professional guinea pigs?}

Risk is an inherent part of biomedical research and of Phase I trials, in particular. While some compounds tested in Phase I trials have already been approved and tested by millions of consumers, others are experimental and have only been tried on dogs and rats before. And the fact that subjects receive doses much larger than those consumed by the public once the drug is approved only compounds the risk they face. Eliminating Phase I trials is not an option because it would only transfer risk to the later trial phases and to the overall population who would later consume the drugs. Maintaining Phase I trials but ending the practice of providing financial compensation — recruiting only altruistic volunteers—won't work either. This solution might seem compelling but it would considerably slow or stop drug development altogether. After all, asking citizens to place themselves in harm's way, taking drugs they don't need to assess their toxicity, would be beyond the call of duty for most. Even very altruistic subjects might be hesitant to volunteer to test drugs for a pharmaceutical industry they might perceive as not trustworthy. Finally, it would also deprive poor research subjects of muchneeded income. 
Since continuing to rely on paid professional trial subjects seems to be necessary, at least for the time being, the following recommendations aim not to eliminate risk but to minimize it, while also making the risks that do exist more transparent. A related goal is to address the exploitation of trial subjects by making sure their rights not only as subjects, but also as workers, are respected. Some recommendations directly challenge the pharmaceutical industry's current arrangements — and interests — and thus may be very hard to implement.

The first recommendation is to keep detailed records documenting the participation of paid volunteers in trials. Of particular relevance is information about the identity of volunteers, as well as how often, where, and in which trials they participate. Data about ADRs (Adverse Drug Reactions) or other events should also be recorded. The best way of implementing this recommendation would be to create a centralized register. The FDA would be a good institution to house such a register, if it decides to overcome its current timidity about overseeing the conditions in which paid subjects volunteer for Phase I trials. Such a register would enhance the accountability of the pharmaceutical industry and its CROs, and should be paired with the elimination of industry-hired IRBs, relying instead on publicly funded review boards.

This point relates to a second recommendation: to carry out scientific, impartial studies of possible drug interactions not only in the short term, but also over extended periods of time, in order to document and prevent long-term toxicity and synergistic effects.

Third, we need to recognize volunteers' participation as laborers, and ensure they receive better working conditions and proper compensation. This recommendation acknowledges that paid subjects place their bodies at the service of scientific research; they are not just contributing their "time and effort" but performing, as they recognize, "a weird type of work." They deserve a full contractual relationship, affording them labor protections guaranteed to other workers in risky occupations.

Subjects may have an active role to play in regulating working conditions as well. They could create a publicly accessible register of trial sites where trial subjects could evaluate the conditions they face in different facilities, from the quality of the staff to the food as well as other items of interest to participants. Guinea Pig Zero's report cards, which rate the conditions at different trial sites, 
might be a good start. However, the full implementation of this recommendation

would require volunteers to take on a much larger and sustained effort they might not be willing to undertake.

A final recommendation is to restrict the number of trials, diminishing both drug exposure and potentially adverse effects. Since this would change some aspects of the market-based organization of clinical trials research, it could encounter stiff resistance from the pharmaceutical industry. However, from the point of view of larger social interests, there is no harm incurred by this measure. Most trials are conducted on "me-too drugs," testing slightly altered versions of drugs that are already on the market. This increases the industry's profits, allowing them to extend patent protection and capture or expand market share, while exposing volunteers to risk with no scientific advancement. Perhaps providing tax incentives for trials that test new, experimental drugs, while levying taxes on "me-too drug" trials would aid in the implementation of this recommendation.

There are potential obstacles, of course. Currently, the Food and Drug Administration tends more towards facilitating a good business climate than public intervention, and might not assist in the implementation of these recommendations. In addition, some recommendations also challenge the industry's dependence upon paid research subjects. Finally, paid subjects might not endorse any policy recommendations that limit their immediate ability to enroll in trials even if it would benefit them in the long run.

\section{References}

ABADIE, R. A Guinea Pig's Wage: Risk and Commoditization in Clinical Trials Drug Research in America In: MERRILL, S.; BAER, H. (Eds.). Killer Commodities: A Critical Anthropological Examination of Corporate Products and Public Health. New York: Rowman \& Littlefield, 2008. 438 p.

ABADIE, R. The Professional Guinea Pig: Big Pharma and the Risky World of Human Subjects. Durham, NC: Duke University Press, 2010. 200 p.

APPADURAI, A. The Social Life of Things: Commodities in Cultural Perspective. Cambridge; New York, NY: Cambridge University Press.

BIEHL, J. Will to Live: AIDS Therapies and the Politics of Survival. Princeton, NJ: Princeton University Press, 2007. 472 p. 
CSORDAS, T. The Sacred Self: A Cultural Phenomenology of Charismatic Healing. Berkeley, CA: University of California Press, 1994. 327p.

DI LEONARDO, M. Exotics at Home: Anthropologies, Others and American Modernity. Chicago, IL: University of Chicago Press, 1998. 464 p.

ELlOTT, C. White Coat, Black Hat: Adventures in the Dark Side of Medicine. Boston, MA: Beacon Press, 2010. 213 p.

FARMER, P. Pathologies of Power: Health, Human Rights, and the New War on the Poor. Berkeley, CA: University of California Press. 2004. 429 p.

FISHER, J. Medical Research for Hire: The Political Economy of Pharmaceutical Clinical Trials. Rutgers, NJ: Rutgers University Press. 2008. 272 p.

GEEST, V. et al. The Anthropology of Pharmaceuticals: A Biographical Approach. Annual Review of Anthropology, v. 25, p. 153-178, 1996.

HELMS, R. Guinea Pig Zero: An Anthology of the Journal for Human Research Subjects. Louisiana, LA.: Garnett County Press. 2005. 260 p.

LEVIN, B. Consensus and Controversy in the Treatment of Catastrophically Ill Newborn. In: MURRAY, T. H.; CAPLAN, A. L. (Eds.). Which Babies Shall Live? New Jersey: Humana Press, 1989. 224 p.

LIEBENEAU, J. Medical Science and Medical Industry: The Formation of the American Pharmaceutical Industry. Baltimore, MD: The Johns Hopkins University Press, 1987. 222 p. LOCK, M.; FARQUHAR, J. (Eds.). Beyond the Body Proper: Reading the Anthropology of Material Life. Durham, NC: Duke University Press, 2007. 704 p.

MARSHALL, P. Anthropology and bioethics. Medical Anthropology Quarterly, v. 6, n.1, p. 49-73, 1992.

MARSHALL, P.; KOENIG, B. Accounting for Culture in a Globalized Ethics. Journal of Law, Medicine, and Ethics, v. 32, n. 2, p. 252-266, 2004.

MARTIN, E. The Woman in the Body: A Cultural Analysis of Reproduction. Boston, MA: Beacon Press, 1987. 276 p.

MARX, K. Capital. V. 1. A Critique of Political Economy. London, Penguin Books, 1976. $1152 \mathrm{p}$.

OLDANI, M. Thick Prescriptions: Towards and Interpretation of Pharmaceutical Sales Practices. Medical Anthropology Quarterly, v. 18, p. 328-356, 2004.

PETRYNA, A. Globalizing Human Subjects Research. In: Petryna A, LAKOFF A., KLEINMAN, A. (Eds.) Global Pharmaceutics: Ethics, Markets and Practices, Durham, NC: Duke University Press, 2006. 312 p.

PETRYNA, A. When Experiments Travel: Clinical Trials and the Global Search for Human Subjects. Princeton, NJ: Princeton University Press, 2009. 272 p. 
RAJAN, S. Bio capital: The Constitution of Postgenomic Life. Durham, NC: Duke University Press, 2006. 360 p.

ROSE, N. The Politics of Life Itself: Biomedicine, Power, and Subjectivity in the TwentyFirst Century. Princeton, NJ: Princeton University Press, 2007. 350 p.

SCHEPER-H.; LOCK, M. A Mindful Body: A Prolegomenon to Future Work in Medical Anthropology. Medical Anthropology Quarterly, v. 1, p. 6-41. 1987.

SCHEPER-H.; WACQUANT, L. Commodifying Bodies. London, Sage Publications, 2003. $200 \mathrm{p}$.

SILVERMAN, M. Pills, Profits and Politics. Berkeley, CA: University of California Press, 1974. p. 403.

\section{Note}

${ }^{1}$ This research was approved by the Institutional Review Board (IRB) of the Graduate Center, City University of New York (CUNY). 
"A tortura da economia moderada": explorando o mundo dos sujeitos de pesquisa profissionais e suas implicaçoes éticas

Este artigo documenta o surgimento do sujeito da pesquisa profissional na Fase I de ensaios clínicos que testam a segurança de medicamentos em desenvolvimento. Baseado em pesquisas etnográficas entre sujeitos autoidentificados "cobaias profissionais" na Filadélfia, EUA, o estudo examina suas experiências e opiniōes sobre a condução dos ensaios e os riscos que assumem na participação. $\mathrm{O}$ autor argumenta que os riscos apresentados pela participação contínua, como a exposição às interaçôes medicamentosas potencialmente perigosas, são minimizados ou ignorados pelos sujeitos de pesquisa devido à perspectiva de ganhos financeiros. Os riscos para as cobaias profissionais também são ignorados pela indústria farmacêutica, que se tornou dependente da participação habitual de sujeitos de pesquisa experientes. Argumentando que os incentivos financeiros comprometem o imperativo ético de consentimento informado a ser dado livremente pelos voluntários, esta pesquisa confirma a necessidade de reformar as políticas que regulam a participação de sujeitos pagos na Fase I de ensaios clínicos.

> Palavras-chave: ensaios clínicos; sujeitos; risco; ética; pesquisa qualitativa. 